\title{
Redundancy Allocation for Series Parallel Systems with Multiple Constraints and Sensitivity Analysis
}

\author{
S. V. Suresh Babu ${ }^{1}$, D.Maheswar ${ }^{2}$, G. Ranganath ${ }^{3}$ Y.Vijaya Kumar ${ }^{\mathrm{d}} \quad$ G.Sankaraiah ${ }^{\mathrm{e}}$ \\ ${ }^{1}$ (Mechanical Engg Dept, Adhiyamaan College of Engg, Hosur - 635109, T. N. State) India \\ ${ }_{2}^{2}$ (Principal, M.N.R.College of Engg, Sangareddy Dist, Hyderabad-500 072, A.P.State, India \\ ${ }^{3}$ (Principal, Adhiayamaan College of Engg, Hosur - 635109, T.N.State) India. \\ d.(Principal, Sri Bhagavan Mahaveer Jain College of Engg, Bangalore, K.A. State,) India. \\ e. (Professor, Mech Engg Dept G.Pulla Reddy College of Engg, Kurnool, A.P.State,) India.
}

\begin{abstract}
The main objective of this paper is to make redundancy allocation for Series Parallel Systems with multiple constraints in order to determine the component reliabilities $\left(\mathrm{r}_{\mathrm{j}}\right)$, the number of components in each stage $\left(\mathrm{x}_{\mathrm{j}}\right)$, stage reliability $\left(R_{j}\right)$ and the System Reliability $\left(R_{s}\right)$ in each stage for the given Cost and Weight constraints to maximize the System Reliability. The system used is a Series - Parallel configuration by using optimization techniques, such as Lagrangean Multiplier Method and Dynamic Programming. The Reliability Model has been developed for Cost and Weight constants. The authors in their work make an attempt to negotiate the impact of Cost and Weight as constants for the Mathematical Function $\quad r_{j}=\frac{\pi}{2} \cdot \tan ^{-1}\left(\frac{c_{j}}{b_{j}}\right)^{\frac{1}{d_{j}}}$ The developed models are handy with high application value particularly in the case of Integrated Reliability Model for redundant systems with Series - Parallel configuration. Generally reliability is treated as the function of Cost but in any given practical situation apart from cost other constraint like Weight will have hidden impact on the reliability of the system. In this model the Lagrangean technique is implemented to determine the number of components as integers and the variation in Cost and weight is found more, this leads to introduce Dynamic Programming technique by taking the number of components as real numbers. The model has yielded very encouraging results and it can be applied to any type of system, simple or complex. The advantage of this model is very flexible and requires little processing time.
\end{abstract}

Keywords: System Reliability; Stage Reliability; Series - Parallel System; Multiple constraints;

\section{INTRODUCTION}

This Paper treats a System with many stages in Series Parallel configuration. To build high reliability in to a system, a Design Engineer usually resorts to redundant units for each stage, but must stay with in the resources available, i.e. constraints improved on the design, such as Cost and Weight. The optimum redundancy depends on Reliability, Cost and Weight etc. of each stage. The reliability of a System can be maximized subject to the resource constraints to determine the optimum number of redundant components for each stage, when the reliability of each component is known in other situations, the reliability of the system can be maximized subject to the resource constraint to determine the reliability of the components in the system when the number of Redundant units in each stage is known. As on Today the literature on maximization of System Reliability problems are considered, there is no much work reported on Integrated Reliability Model for Redundant Systems with multiple constants. In this scenario the authors want to make an attempt to optimize the Reliability of a System with Multiple Constants.To study and optimize the Integrated Reliability Model for Redundant Systems with Multiple Constraints is considered with Cost and Weight as constants, for the given known mathematical function

$$
r_{j}=\frac{\pi}{2} \cdot \tan ^{-1}\left(\frac{c_{j}}{b_{j}}\right)^{\frac{1}{d_{j}}}
$$

\section{STATEMENT OF THE PROBLEM}

To determine the unknowns i.e. the number of components $\left(\mathrm{x}_{\mathrm{j}}\right)$, the component reliabilities $\left(\mathrm{r}_{\mathrm{j}}\right)$ the stage reliability $\left(\mathrm{R}_{\mathrm{j}}\right)$ at each stage for a given multiple constants to maximize the system reliability. Though Cost has direct relation in maximizing System Reliability, the indirect impact of weight as on additional constraint in optimizing the Reliability of a Redundant System presents a novel beginning in the mentioned area of research. The Series - Parallel Systems are considered with Cost and Weight as constraints to maximize the Reliability of a redundant system as its objective function.

\section{ASSUMPTIONS OF THE MODEL}

1. All the components in each stage are assumed to be identical.

2. The components are assumed to be statistically independent i.e. the failure of one component does not affect the performance of the other components in the system. 
3. A component is either in working condition or nonworking condition.

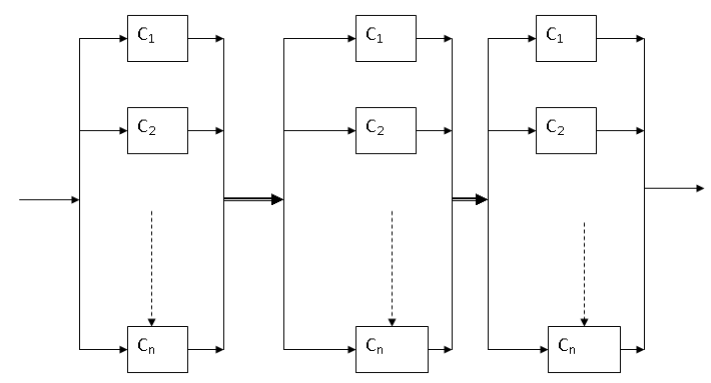

FIG 1: SERIES-PARALLEL CONFIGURATION

\section{NOMENCLATURE:}

$\mathrm{R}_{\mathrm{s}}=$ System Reliability.

$R_{j}=$ Stage Reliability, $0<R_{j}<1$

$\mathrm{F}=$ Lagrangean function

$r_{j}=$ Reliability of each component in stage $\mathrm{j}, 0<\mathrm{r}_{\mathrm{j}}<1$.

$\mathrm{x}_{\mathrm{j}}=$ No. of components in stage $\mathrm{j}$.

$c_{j}=$ Cost coefficient of each component in stage $j$

$\mathrm{w}_{\mathrm{j}}=$ Weight coefficient of each component in stage $\mathrm{j}$.

$\mathrm{C}_{\mathrm{o}}=$ Maximum allowable System Cost.

$\mathrm{W}_{\mathrm{o}}=$ Maximum allowable System Weight.

$b_{j}=$ Scaling factor for stage ' $\mathrm{j}$ ' used in the function

$d_{j}=$ Shaping factor for stage ' $j$ ' used in the function

$\mathrm{p}_{\mathrm{j}}=$ Constant used in weight function .

$\mathrm{q}_{\mathrm{j}}=$ Constant used in weight function

\section{MATHEMATICAL MODEL}

Consider that there are ' $n$ ' statistically independent stages in Series with $\mathrm{x}_{\mathrm{j}}$ statistically independent in each stage.

System Reliability for the given cost function

$$
\mathrm{R}_{\mathrm{s}}=\prod_{j-1}^{n} R_{j}=\prod_{j=1}^{n}\left[1-\left(1-r_{j}\right)^{x_{j}}\right]
$$

Subjected to $\sum_{j=1}^{n} c_{j} \cdot x_{j} \leq C_{0}$

$$
\sum_{j=1}^{n} w_{j} . x_{j} \leq W_{0}
$$

Non negativity restriction $x_{j}$ is an integer and $r_{j}, R_{j}>0$

\section{MATHEMATICAL FUNCTION}

Cost co efficient of each component in stage ' $j$ ' is derived from the following relationship between Cost and Reliability. $r_{j}=\frac{\pi}{2} \cdot \tan ^{-1}\left(\frac{c_{j}}{b_{j}}\right)^{\frac{1}{d_{j}}}$

Where $c_{j}$ is cost constraint and $b_{j}, d_{j}$ are constants.

\section{PROBLEM FORMULATION}

System Reliability for the given cost function

$$
\mathrm{R}_{\mathrm{s}}=\prod_{j-1}^{n} R_{j}
$$

Cost coefficient of each unit in stage ' $\mathrm{j}$ ' is derived from the following relationship between cost and reliability

$$
\begin{aligned}
& r_{j}=\frac{\pi}{2} \cdot \tan ^{-1}\left(\frac{c_{j}}{b_{j}}\right)^{\frac{1}{d_{j}}} \\
& c_{j}=b_{j} \cdot\left[\tan \left(\frac{r_{j}}{\pi / 2}\right)^{d_{j}}\right]
\end{aligned}
$$

Since cost constraint is linear in $\mathrm{x}_{\mathrm{j}}$

$$
\sum_{j=1}^{n} c_{j} \cdot x_{j} \leq C_{O}
$$

Similarly weight constraint is also linear in $\mathrm{x}_{\mathrm{j}}$

$$
\sum_{j=1}^{n} w_{j} \cdot x_{j} \leq W_{O}
$$

Substituting equations (6) and (7) in (8) and (9) we get the following relation

$$
\begin{aligned}
& \left.\sum_{j=1}^{n}\left[\left(b_{j} \cdot \tan \left(\frac{r_{j}}{\pi / 2}\right)^{d_{j}}\right]\right) x_{j}\right]-C_{0} \leq 0 \\
& \sum_{j=1}^{n}\left[\left(p_{j} \cdot\left[\tan \left(\frac{r_{j}}{\pi / 2}\right)^{q_{j}}\right]\right) x_{j}\right]-W_{0} \leq 0
\end{aligned}
$$

The number of components at each stage $x_{j}$ is given through the relation

$$
x_{j}=\frac{\ln \left(1-R_{j}\right)}{\ln \left(1-r_{j}\right)}
$$

Maximize $R_{s}=\prod_{j=1}^{n}\left[1-\left(1-r_{j}\right)^{x_{j}}\right]$ 
Subject to the constraints

$$
\begin{aligned}
& \sum_{j=1}^{n}\left[\left(b_{j} \cdot\left[\tan \left(\frac{r_{j}}{\pi / 2}\right)^{d_{j}}\right]\right) \cdot \frac{\ln \left(1-R_{j}\right)}{\ln \left(1-r_{j}\right)}\right]-C_{O} \leq 0 \\
& \sum_{j=1}^{n}\left[\left(p_{j} \cdot\left[\tan \left(\frac{r_{j}}{\pi / 2}\right)^{q_{j}}\right]\right) \cdot \frac{\ln \left(1-R_{j}\right)}{\ln \left(1-r_{j}\right)}\right]-W_{O} \leq 0
\end{aligned}
$$

\section{LAGRANGEAN METHOD}

Solving the proposed formulation using Lagrangean method.

$$
\begin{aligned}
& F=R_{s}+\lambda_{1}\left[\left\{\sum_{j=1}^{n}\left\{\left(b_{j} \cdot\left[\tan \left\{r_{j} /(\pi / 2)\right\}^{d_{j}}\right] \cdot \frac{\ln \left(1-R_{j}\right)}{\ln \left(1-r_{j}\right)}\right)\right\}\right\}-C_{0}\right]+ \\
& \lambda_{2}\left[\left\{\sum_{j=1}^{n}\left\{\left(p_{j} \cdot\left[\tan \left\{r_{j} /(\pi / 2)\right\}^{q_{j}}\right] \frac{\ln \left(1-R_{j}\right)}{\ln \left(1-r_{j}\right)}\right)\right\}\right\}-W_{0}\right]=0
\end{aligned}
$$

where $\lambda_{1}$ and $\lambda_{2}$ are Lagrangean multipliers and $F$ being Lagrangean function.

The number of components in each stage $\left(\mathrm{x}_{\mathrm{j}}\right)$, optimum component reliability $\left(r_{j}\right)$, stage reliability $\left(R_{j}\right)$ and the system reliability $\left(\mathrm{R}_{\mathrm{s}}\right)$ are derived from the Lagrangean method. The method provides real valued solution with reference to cost and weight.

The stationary point can be obtained by differentiating the Lagrangean function with respect to $R_{j}$ $\mathrm{r}_{\mathrm{j}}, \lambda_{1}$, and $\lambda_{2}$

\section{RESULTS AND DISCUSSIONS}

The following reliability design tables related to cost and weight are calculated by using the component reliabilities and the number of components derived from Lagrangean method.

\subsection{Case Study:}

Consider the case of a Mechanical system with three stages for which the component Reliability is given by the equation (4).

To determine the optimum component reliability, stage reliability, number of components in each stage and the System Reliability not to exceed the system cost Rs.250, Weight of the system $300 \mathrm{~kg}$. The component Reliabilities, Stage Reliabilities, Number of components in each stage and the System Reliability are determined by solving the above mathematical function by using MATLAB Version 7.10 and are presented in the following tables.

\subsection{Cost and Weight as constraints:}

9.2.1 Reliability Design Without $x_{j}$ rounding off:
Table I. Reliability design relating to Cost in (Rs):

\begin{tabular}{|l|l|l|l|l|l|}
\hline Stage & $\mathrm{r}_{\mathrm{j}}$ & $\mathrm{R}_{\mathrm{j}}$ & $\mathrm{x}_{\mathrm{j}}$ & $\mathrm{c}_{\mathrm{j}}$ & $\mathrm{c}_{\mathrm{j} .} \mathrm{x}_{\mathrm{j}}$ \\
\hline 01 & 0.4951 & 0.9110 & 3.54 & 17.3 & 59.00 \\
\hline 02 & 0.4940 & 0.9820 & 5.9 & 20.0 & 118.00 \\
\hline 03 & 0.3892 & 0.8964 & 4.6 & 16.07 & 73.00 \\
\hline \multicolumn{5}{|l|}{ Total Cost } & 250.00 \\
\hline
\end{tabular}

Table II. Reliability design relating to Weight $(\mathrm{Kg})$ :

\begin{tabular}{|c|l|l|l|l|l|}
\hline Stage & $\mathrm{r}_{\mathrm{i}}$ & $\mathrm{R}_{\mathrm{i}}$ & $\mathrm{x}_{\mathrm{i}}$ & $\mathrm{c}_{\mathrm{i}}$ & $\mathrm{c}_{\mathrm{i} .} \mathrm{x}_{\mathrm{i}}$ \\
\hline 01 & 0.4951 & 0.9110 & 3.54 & 17.3 & 59.00 \\
\hline 02 & 0.4940 & 0.9820 & 5.9 & 27.6 & 163.00 \\
\hline 03 & 0.3892 & 0.8964 & 4.6 & 17.0 & 78.00 \\
\hline \multicolumn{5}{|l}{ Total Cost } \\
\hline
\end{tabular}

\section{System Reliability 0.8011}

\subsubsection{Reliability Design with $x_{j}$ rounding off:}

The reliability design is reestablished by considering the values of to be integers (by rounding off the value of to the nearest integer) and the relevant results relating to cost and weight are presented in the following table, further giving the information by calculating the variation due to cost and weight and the system reliability (before and after rounding off).Table: 3Reliability design relating to Cost in Rupees.

Table III. Reliability design relating to Cost in (Rs) :

\begin{tabular}{|c|c|c|c|c|c|}
\hline Stage & $\mathrm{r}_{\mathrm{j}}$ & $\mathrm{R}_{\mathrm{j}}$ & $\mathrm{x}_{\mathrm{j}}$ & $\mathrm{c}_{\mathrm{j}}$ & $\mathrm{c}_{\mathrm{j} .} \mathrm{x}_{\mathrm{j}}$ \\
\hline 01 & 0.4951 & 0.9350 & 4 & 17.30 & 69.20 \\
\hline 02 & 0.4940 & 0.9832 & 6 & 20.00 & 120.00 \\
\hline 03 & 0.3892 & 0.9150 & 5 & 16.67 & 80.35 \\
\hline \multicolumn{5}{|l}{ Total Cost } & 269.55 \\
\hline
\end{tabular}

Table IV. Reliability design relating to Weight (Kg):

\begin{tabular}{|c|c|c|c|c|c|}
\hline Stage & $r_{j}$ & $R_{j}$ & $X_{j}$ & $W_{j}$ & $W_{j} . X_{j}$ \\
\hline 01 & 0.4951 & 0.9350 & 4 & 17.30 & 69.20 \\
\hline 02 & 0.4940 & 0.9832 & 6 & 27.60 & 165.60 \\
\hline 03 & 0.3892 & 0.9150 & 5 & 17.00 & 85.00 \\
\hline \multicolumn{5}{|r}{ Total Cost } & 319.80 \\
\hline
\end{tabular}

System Reliability $\left(\mathbf{R}_{\mathrm{s}}\right)=\mathbf{0 . 8 4 1 1}$

Variation in total Cost $=7.82 \%$

Variation in total Weight $=6.60 \%$

Variation in System Reliability $=4.88 \%$

\section{DYNAMIC PROGRAMMING:}

To optimize the design by using Dynamic Programming the same case problem discussed in the preceding chapter has been considered by taking the values of Component Reliabilities $\left(r_{j}\right)$, the number of components in each stage $\left(\mathrm{x}_{\mathrm{j}}\right)$, Stage Reliabilities $\left(\mathrm{R}_{\mathrm{j}}\right)$ and the System Reliability $\left(R_{s}\right)$ as inputs. This Approach is particularly useful in optimizing the design with the values of $\mathrm{x}_{\mathrm{j}}$ 's to be integers, which are highly appreciated for practical implementation to real life problems. The number of components, which was taken as a real number has been changed to an integer. The output has come in two stages with corresponding Stage Reliability is shown in Table V. 
Table V DYNAMIC PROGRAMMING - STAGE 1:

\begin{tabular}{|c|c|}
\hline $\begin{array}{c}\text { No.of } \\
\text { Components }\end{array}$ & Stage Reliability \\
\hline 01 & 0.4951 \\
\hline 02 & 0.7450 \\
\hline 03 & 0.8712 \\
\hline 04 & 0.9350 \\
\hline 05 & 0.9671 \\
\hline 06 & 0.9834 \\
\hline
\end{tabular}

\begin{tabular}{|l|l|}
\hline 07 & 0.9916 \\
\hline 08 & 0.9957 \\
\hline 09 & 0.9978 \\
\hline 10 & 0.9989 \\
\hline 11 & 0.9994 \\
\hline 12 & 0.9997 \\
\hline 13 & 0.9998 \\
\hline 14 & 0.9999 \\
\hline
\end{tabular}

Table VI DYNAMIC PROGRAMMING - STAGE 2:

\begin{tabular}{|c|c|c|c|c|r|r|r|r|r|}
\hline \multirow{2}{*}{$\begin{array}{c}\text { No.of } \\
\text { Components }\end{array}$} & \multicolumn{9}{|c|}{ Stage Reliability } \\
\hline & 1 & 2 & 3 & 4 & 5 & 6 & 7 & 8 & 9 \\
\hline 04 & 0.4340 & 0.5542 & 0.4309 & & & & & & \\
\hline 05 & 0.4618 & 0.6480 & 0.6484 & 0.4626 & & & & & \\
\hline 06 & 0.4777 & 0.6955 & 0.7583 & 0.6961 & 0.4786 & & & & \\
\hline 07 & 0.4857 & 0.7194 & 0.8138 & 0.8140 & 0.7202 & 0.4867 & & & \\
\hline 08 & 0.4898 & 0.7315 & 0.8417 & 0.8736 & 0.8422 & 0.7324 & 0.4908 & & \\
\hline 09 & 0.4918 & 0.7376 & 0.8559 & 0.9036 & 0.9039 & 0.8565 & 0.7386 & 0.4929 & \\
\hline 10 & 0.4929 & 0.7407 & 0.8630 & 0.9188 & 0.9349 & 0.9192 & 0.8637 & 0.7417 & 0.4940 \\
\hline 11 & 0.4934 & 0.7422 & 0.8666 & 0.9265 & 0.9507 & 0.9508 & 0.8638 & 0.8637 & 0.7433 \\
\hline 12 & 0.4937 & 0.7430 & 0.8684 & 0.9303 & 0.9586 & 0.9668 & 0.9588 & 0.9309 & 0.8692 \\
\hline 13 & 0.4939 & 0.7434 & 0.8694 & 0.9323 & 0.9626 & 0.9749 & 0.9750 & 0.9629 & 0.9329 \\
\hline 14 & 0.4939 & 0.7436 & 0.8698 & 0.9333 & 0.9646 & 0.9789 & 0.9831 & 0.9791 & 0.9458 \\
\hline 15 & 0.4939 & 0.7437 & 0.8701 & 0.9338 & 0.9657 & 0.9810 & 0.9872 & 0.9873 & 0.9812 \\
\hline
\end{tabular}

Table VII DYNAMIC PROGRAMMING - STAGE 3:

\begin{tabular}{|c|c|c|c|r|r|r|r|}
\hline \multirow{2}{*}{$\begin{array}{c}\text { No.of } \\
\text { Components }\end{array}$} & \multicolumn{7}{|c|}{ Stage Reliability } \\
\hline & 1 & 2 & 3 & 4 & 5 & 6 & 7 \\
\hline 09 & 0.3400 & 0.5103 & 0.5854 & 0.5581 & 0.5070 & & \\
\hline 10 & 0.3517 & 0.5477 & 0.6284 & 0.6527 & 0.5932 & 0.5253 & \\
\hline 11 & 0.3638 & 0.5687 & 0.6745 & 0.7006 & 0.6937 & 0.6146 & \\
\hline 12 & 0.3700 & 0.5861 & 0.6979 & 0.7520 & 0.7447 & 0.7188 & \\
\hline 13 & 0.3762 & 0.5961 & 0.7218 & 0.7780 & 0.8269 & 0.7716 & \\
\hline 14 & 0.3794 & 0.6061 & 0.7341 & 0.8047 & 0.8000 & 0.8281 & 0.7881 \\
\hline 15 & 0.3842 & 0.6113 & 0.7464 & 0.8184 & 0.8553 & 0.8568 & 0.8458 \\
\hline
\end{tabular}

\subsection{RELIABILITY DESIGN- COST:}

From the Dynamic Programming tables the maximum System Reliability is 0.6721 with a total COST of Rs. 269.55 and the corresponding optimal values are as shown below.

Table VIII: Reliability design relating to Cost in (Rs):

\begin{tabular}{|c|c|c|c|c|c|}
\hline STAGE & $\mathrm{r}_{\mathrm{j}}$ & $\mathrm{R}_{\mathrm{j}}$ & $\mathrm{x}_{\mathrm{j}}$ & $\mathrm{c}_{\mathrm{j}}$ & $\mathrm{c}_{\mathrm{j}} \cdot \mathrm{x}_{\mathrm{j}}$ \\
\hline 01 & 0.4951 & 0.9350 & 4 & 17.30 & 69.2 \\
\hline 02 & 0.4940 & 0.7583 & 6 & 20.00 & 120.00 \\
\hline 03 & 0.0 .3892 & 0.9480 & 5 & 16.07 & 80.35 \\
\hline \multicolumn{5}{|c|}{ T 0 T A L C O S T } & 269.55 \\
\hline
\end{tabular}

\subsection{RELIABILITY DESIGN - WEIGHT:}

From the Dynamic Programming tables the maximum System Reliability is 0.6721 with a total WEIGHT of 319.80 and the corresponding optimal values are as shown below.
Table IX: Reliability design relating to Weight in $(\mathrm{Kg})$

\begin{tabular}{|c|c|c|c|c|c|}
\hline STAGE & $r_{i}$ & $\mathrm{R}_{\mathrm{i}}$ & $\mathrm{x}_{\mathrm{i}}$ & $\mathrm{w}_{\mathrm{i}}$ & $\mathrm{x}_{\mathrm{i} \cdot \mathrm{W}_{\mathrm{j}}}$ \\
\hline 01 & 0.4951 & 0.9350 & 4 & 62.02 & 69.2 \\
\hline 02 & 0.4940 & 0.7583 & 6 & 68.67 & 165.60 \\
\hline 03 & 0.3892 & 0.9480 & 5 & 68.78 & 85.00 \\
\hline \multicolumn{5}{|c|}{7} & 319.80 \\
\hline
\end{tabular}

System Reliability $\quad=0.6721$

Variation in Total Cost $\quad=7.82 \%$

Variation in Total Weight $=6.60 \%$

Variation in System Reliability $=25.14 \%$

11.3 Sensitivity Analysis:

It is observed that when the input data of component reliability is increased 10 percent there 32.43 percent increase in system reliability. Similarly when 10 percent decrease in input data there will be 15.5 percent decrease 
in system reliability is observed. When one factor is varied, keeping other factors constant, variation in Cost and Weight is as shown in Table X.

Table X Sensitivity Analysis:

\begin{tabular}{|c|c|}
\hline \multicolumn{2}{|c|}{ Variation in component reliability $\left(\mathbf{r}_{\mathbf{j}}\right)$} \\
\hline For 10\% increase & For 10\% decrease \\
\hline $\begin{array}{c}\text { COST 26.51\% } \\
\text { increases }\end{array}$ & $\begin{array}{c}\text { COST 29.78\% } \\
\text { increases }\end{array}$ \\
\hline WEIGHT 27.35\% & WEIGHT 22.13\% \\
increases & increases \\
\hline $\begin{array}{c}\text { System Reliability } \\
28 \% \text { increases }\end{array}$ & $\begin{array}{c}\text { System Reliability } \\
15.6 \% \text { increases }\end{array}$ \\
\hline
\end{tabular}

The analysis confirms that the cost and weight are more sensitive to input data.

\section{CONCLUSION}

Primarily this paper is focused in allocating redundancy units with multiple constraints for a reliability system, where in the development of integrated reliability model is discussed in detail. The paper infers that the multiple constraints problem is first treated through Lagrangean method where this method provided a real valued solution and as such may be infeasible for practical implementation. For this reason, the problem solved by Dynamic Programming, which proved a ideal solution to take the number of components in integer values and to find the exact system reliability. The variation of Cost, Weight and System Reliability is analyzed with respect to component reliability in the form of Sensitivity analysis.

This model can also be further investigated for different mathematical functions of interest and also can be applied for Parallel - Series configuration systems, where the application of these models for such systems will be feasible only when the cost of the system is very low.

\section{REFERENCES:}

[1] Misra.K.B., "Dynamic Programming formulation of Redundancy allocation problem", International Journal of Math Educational Science, Technology (U.K), Vol.02, July-September 1971(a), PP.207215.

[2] Balagurusamy.E. "Reliability Engineering", TMH, 1984.

[3] Tillman.F.A., Hwang.C.L., and Way Kuo., "Optimization of System Reliability", Marvel Dekker, New York, 1980.

[4] Kuo.W, Lin.H, Xu.Z, and Zhang.W, "Reliability Optimization with Lagrange Multiplier and Branch and Bound Technique", IEEE Transactions on Reliability, Vol.R-36, No.5, December 1987, PP.624-630.
[5] Dhingra.A.K., "Optimal Apportionment of Reliability and Redundancy in Series Systems under Multiple Objectives", IEEE Transactions on Reliability, Vol.-41, No.4, December 1992, PP. 576-582.

[6] Flehinger.B.J., "System reliability as a function of system age, Effects of intermittent component usage and periodic maintenance", presented at 1959 IRE National Convention, New York, March 1959.

[7] Gopal.K., Aggrawal.K.K, and Gupta.J.S, “A new method for solving Reliability Optimization problem", IEEE Transactions on Reliability, Vol.R-29, No.1, April 1980, PP.36-38.

[8] Gordon.R., "Optimum Component Redundancy for maximum System Reliability”, Operations Research., Vol.5, March 1957, PP.229-243.

[9] Deb.K., "Optimization for Engineering Design: Algorithms and Examples", Prentice-Hall of India private limited, New Delhi, 1995.

[10] Hwang.C.L., Lai.K.C, Tillman.F.A. \& Fan.L.T. "Optimization of System Reliability by the sequential unconstrained minimization technique", IEEE Transactions on Reliability, Vol.R-24, No.2, June 1975, PP.133-135.

[11] S.V.Suresh Babu, Dr.D.Maheswar and Dr.G.Ranganath, "Optimization of System Reliability for Redundant Systems with Multiple Constraints", International Journal on Advanced Sciences in Engineering and Technology (IJAEST), August, 2011, Page No.199-202, Vol.No.2. Issue No.2.

[12] Misra.K.B. "A Method of Solving Redundancy Optimization problems", IEEE Transactions on Reliability. Vol.R-20, No.5, August 1971, PP-117120.

[13] Rosario Romera, Jose E.Valdes and Romulo I.Zequeira, "Active-Redundancy Allocation in Systems", IEEE Transactions on Reliability, Vol.53, No.3, Sep 2004. 